\title{
EMBEDDEDNESS AND COLLABORATIVE VENTURE NETWORKS AMONG KOREAN CONSTRUCTION FIRMS FOR OVERSEAS CONSTRUCTION PROJECTS
}

\author{
JeongWook SON ${ }^{\mathrm{a}}$, Seung Heon $\mathrm{HAN}^{\mathrm{b}}$, Eddy M. ROJAS ${ }^{\mathrm{c}}$ \\ ${ }^{a}$ Department of Architectural Engineering, Ewha Womans University, 120-750 Seoul, Korea \\ ${ }^{b}$ Department of Civil \& Environmental Engineering, Yonsei University, 120-749 Seoul, Korea \\ c School of Engineering, University of Dayton, 300 College Park, Dayton, OH 45469, USA
}

Received 09 Sep 2012; accepted 12 Nov 2012

\begin{abstract}
Finding competent collaborators while executing construction projects overseas is of paramount importance for project success. The partner choice and project performance cannot be understood only from an economic viewpoint because it is constrained by the firms' embeddedness in social relations. Based on this premise, this paper provides not only a theoretical explanation of the impact of structural and relational embeddedness on firms' economic behaviour and outcomes, but also empirical evidence by analysing the collaborative process among Korean construction firms working overseas during the past 18 years. Three conclusions are drawn. First, the inter-firm network, at least asymptotically, has scale-free network properties with variance. Second, the network retained endogamic characteristics in that a great majority of smaller firms had worked with only one large firm, forming strong subgroups. Last, there is a plausible evidence of the impact of both structural embeddedness and relational embeddedness on profits.
\end{abstract}

Keywords: international factors, construction companies, networks, profits.

\section{Introduction}

As the international construction market has become more liberalized and contractors hedge against unpredictable conditions in domestic markets, the importance of expanding overseas has increased. According to Engineering News-Record (Reina, Tulacz 2011), the top 225 international contractors account for $\$ 383.66$ billion $(6.6 \%)$ of the world construction market, whose total volume was $\$ 4.4$ trillion in 2010 (Crosthwaite 2011). This volume is expected to grow $2.3 \%$ annually until 2013 despite the recent economic recession (Hanlon 2009). Besides, intergovernmental trade agreements such as FTAs (Free Trade Areas) and volatile domestic market demands are likely to incite contractors to expand their overseas business or to have access to international markets if they are not already players. Projections for future demand in infrastructure and the built environment indicate that there will be increasing needs for firms to engage in projects around the world (Javernick-Will, Levitt 2009) and the portion of international contractors in the world construction market is expected to reach between $15 \%$ to $20 \%$ in the near future (Han et al. 2007a).

Collaborative ventures have been used in the construction industry to mitigate and avoid expected risks in overseas projects. Large firms want to form collaborative ventures because they want to: (1) take advantage of the partner's specialty area when there are few local specialty contractors; (2) maximize organizational flexibility and effectiveness; and (3) share costs and risks. On the other hand, small/medium sized firms benefit from collaborative ventures as they want to: (1) overcome their inexperience in risk management; (2) gain access to contracts that would be unreachable otherwise; and (3) diversify from intense competition in domestic markets.

While forming collaborative ventures, firms' partner choice and resulting project performance is determined not only by physical, economic, and cultural capital, but also by social capital. There is no single definition of social capital. However, social capital is understood as social connections within social networks that affects certain actions of actors (Coleman 1988). Although social capital was originally conceived to investigate the inequality in accessing powerful positions and privileged information through social connections, the concept has also been used to examine the impact of social relations on firms' economic behaviour and performance (Walker et al. 1997; Nahapiet, Ghoshal 1998; Koka, Prescott 2002). According to Moran (2005), social capital of firms

Corresponding author: JeongWook Son

E-mail:jwson@ewha.ac.kr 
can be effectively modelled by taking both aggregate network structural properties (structural embeddedness) and the strength and quality of relations (relational embeddedness) into account.

In that regard, this paper aims to not only offer theoretical explanation of both structural and relational embeddedness in an inter-firm network for overseas construction projects but also present the result of empirical examination of collaborative venture data. To accomplish the objective, we first present the results of a preliminary survey study on strategic motives for contactors to constitute collaborative ventures for overseas construction projects. Theoretical explanations are then provided to illustrate how partner choice and performance is influenced by structural embeddedness and relational embeddedness in inter-firm networks, while expanding classical neo-economic views. The results of social network analysis, statistical analysis, and ethnographic studies for collaborative venture formation data are presented to address the problem of embeddedness in an inter-firm network. The paper concludes with implications for managing international projects and recommendations for future research.

\section{Theoretical background}

\subsection{Collaborative entry for overseas construction projects}

Executing overseas projects involves a number of risks ranging from those shared with domestic projects to those specific to overseas ventures including political (Ashley 1987), cultural (Javernick-Will, Levitt 2009), economic (Demacopoulos 1989), financial (Han et al. 2004) and institutional risks. Researchers have developed analysis methods that could help in understanding the characteristics of these risks. For instance, Zhi (1995) demonstrated how to effectively identify risks in overseas construction projects and developed a method to assess them. Hastak and Shaked (2000) proposed a model that can be used to quantify the risks involved in international construction projects. Recently, Han et al. (2007b) developed a comprehensive hierarchical framework to examine the causal relationships of profit-influencing factors for international construction projects. Based on the findings in those studies, several decision-making tools for international construction projects have been suggested. For example, Han and Diekmann (2001a, b) proposed a risk-based go/nogo decision-making model. Han et al. (2007a) devised a profit prediction model through factor analysis and multiple regression analysis, maintaining that it can be used to identify probable risks in the early phase of international projects. Lately, Ling et al. (2008) developed five project success level prediction models using multiple linear regression based on data collected from 33 cases in China.

To mitigate and avoid expected risks in overseas projects, strategic alliances have been widely used by firms in intense global competition. A strategic alliance refers to trading partnerships among firms that could enhance the effectiveness of the competitive strategies of participating firms by providing for the mutually beneficial trade of technologies, skills, or products based upon them (Yoshino, Rangan 1995). A collaborative venture, in this paper, refers to a special type of strategic alliance among contractors - in most cases, between a large firm and small/medium-sized firms. A collaborative venture is similar to a joint venture in the sense that firms expect to have opportunities to transfer risks, to utilize partner firms' special skills, to acquire knowledge and experience, to enter new markets, and to gain economies of scale with the formation of a collaborative venture (Ozorhon et al. 2008b; Sillars, Kangari 2004). However, it is different from a joint venture because the parties do not create a new entity such as a corporation or a limited liability company, but are linked by arm's-length relationships such as a subcontract. They also do not share revenues, expense, or control over the projects.

Several research studies have been performed in the construction management domain regarding strategic alliances. Mohamed (2003) examined the relationship between risk factors in international construction projects and performance of international construction joint ventures. Sillars and Kangari (2004) conducted a survey to investigate the connection between projects conditions which can be known at joint venture inception and the success of construction joint ventures. Ozorhon et al. $(2007,2008 \mathrm{a})$ also examined the links among project performance determinants and their influence on project performance in international construction joint ventures. Ozorhon et al. (2008b) delved into the effect of cultural factors and organizational characteristics on international construction joint venture performance. Ho et al. (2009) shed light on the impact of organizational structure on joint venture performance.

\subsection{The problem of embeddedness in networks}

The manner in which social relations affect economic behaviour is an active research question in sociology and economics. By the basic assumptions of neoclassical economics, firms always execute their rational decisions based on perfect information. They are assumed to be connected by arm's-length relationships and pursue self-interested ends; thus they change price or alter present partners following the rule of utility maximization. A firm only determines its price, which supposedly contains all the information needed to make correct decisions. There are not explicit considerations on inter-firm relations. For instance, if ongoing relationships exist among parties, it is believed to be a self-interested and profit-seeking behaviour (Uzzi 1997). However, in reality, a firm is not independent from other firms since its economic behaviour cannot but be constrained by social interactions in firm network. Often times, firms are connected by trust and personal relationships along with contractual relations. Granovetter (1985) termed such a process, by which ongoing social relationships affect 
economic behaviour, embeddedness. He contended that almost all economic behaviours are embedded in social relations that shape economic processes in a way that neoclassical economics has not recognized.

Embeddedness has influence on the economic behaviour of firms in two dimensions - structural embeddedness and relational embeddedness (Granovetter 1985). Structural embeddedness pertains to the overall configuration of network structure such as presence of relations and patterns of relations including density, connectivity, and hierarchy. In contrast, relational embeddedness concerns the particular quality of relations that actors relate (Nahapiet, Ghoshal 1998). In other words, whereas structural embeddedness relates to the extent to which firms can reach business-related information and resources in the network, relational embeddedness is concerned with how much of this potential will be realized (Moran 2005). For instance, even though a firm may seem to maintain favourable relations with several competent partners and occupies a superior position in future business opportunities - structural embeddedness, it can be affected by past experiences, trustworthiness, reciprocity, and alliance stipulations on how likely partners are willing to share accesses to critical information and provide resources and know-how, this is relational embeddedness.

Theoretical investigations have been made to shed light on the problem of embeddedness, such as why firms often make economically irrational decisions regarding their relations with other firms and rely on trust and personal relationships (Asanuma 1985) rather than on maximizing cost efficiency. Some researchers have borrowed the Simon's (1957) classical model of human rationality. According to this model, economic agents are boundedly rational in the sense that they often use heuristics to make decisions instead of sophisticated decision-making processes because they only have limited cognitive capabilities to cope with all the matters happening in highly complex markets. Williamson (1981) applied these ideas into a conventional economic framework - transaction cost theory - by adding a more realistic assumption that bounded rationality makes it cost-efficient and feasible to replace an atomistic market based on arm's-length contracts with inter-firm networks composed of personal and long-term relations because endlessly repetitive negotiations in complex networks are prohibitively expensive. Likewise, Romo and Schwartz (1995) argued that decision makers with bounded rationality in firms often place a high emphasis on mitigating uncertainty in a complex business environment, so that ephemeral inter-firm relations come to mature into long-term relationships. Uzzi (1997) suggested a more practical perspective explaining that such behaviours appear to be irrational but they are still forego purely selfish behaviour. He pointed out that firms consciously and strategically keep close relations with one another to increase profitability. By pre-empting a superior position in a firm network, a company can benefit from the increased chance to get business-related information and competitive resources.
Several research efforts have focused on understanding real world problems using the concept of embeddedness, despite of the indeterminate implications of embeddedness originated from the discrepancy between the concrete propositions in economics and the broad statements in social research (Uzzi 1997). Provan (1993) examined the emergence of opportunism in a supplierbuyer network. He maintained that the opportunistic behaviour of a supplier declines at increasing levels of embeddedness in supplier-buyer networks. Romo and Schwartz (1995) studied the embeddedness of migrated manufacturing establishments in regional production networks. They found that the migration of manufacturing establishments is more consistent with structural embeddedness predictions than comparative-cost predictions, which indicates that firms prefer cultivating long-term relations rather than gaining immediate profit. Gnyawali and Madhavan (2001) developed a conceptual model of how embeddedness influence the flow of assets, information, and status among network members. Jack and Anderson (2002) qualitatively examined the role of embeddedness in the entrepreneur in rural areas. They found that embeddedness plays a key role in shaping and sustaining businesses by creating opportunity and improving performance. Schalk and Torenvlied (2010) proposed a theory of the effect of inter-organizational network on public agent performance from an embeddedness perspective. Moran (2005) examined the impact of managers' embeddedness on their managerial performance. The results indicated that embeddedness plays a strong role in sales performance as well as product and process innovation.

\subsection{Social network analysis}

A social network is a social structure made of nodes that are connected by one or more specific types of relations (ties), such as friendship, firm alliances, and international trades. Social network analysis (SNA) is a set of techniques used to understand the ecology of social networks by description, visualization, and statistical modelling (van Duijn, Vermunt 2006). In SNA, nodes and their behaviours are viewed as interdependent rather than independent, ties among nodes are paths for transfer or flow of resources, and network models focusing on individuals regard the network structure as environment that constrains a node's behaviour (Wasserman, Faust 1994).

Since Loosemore (1998) proposed social network analysis as an alternative research method in the construction engineering and management domain, the fundamental ideas and theoretical backgrounds of SNA have been introduced and several social network studies have been performed due to its theoretical and methodological merits. A few research studies have regarded construction projects and project teams as information networks in which information transfers along the relations and are shared among members (Paul et al. 2008; Pryke 2005; Mead 2001; Gandhi, Sauser 2008; Siva, London 2012). 
In summary, although collaborative ventures have been widely used by firms in overseas projects to mitigate and avoid expected risks, there have been few studies investigating how inter-firm networks evolve over time. Most previous studies on strategic alliances have focused on identifying success factors and potential risks at the macro level. However, the concept of embeddedness, where firms are not independent from one another but are constrained by social interactions in inter-firm networks, can be helpful in explaining an underlying mechanism by which firms form relations with partners.

\section{Preliminary study: strategic motives for collaborative entry}

Prior to investigating the effects of embeddedness in inter-firm networks, we conducted a survey to collect information on why firms want to form collaborative ventures for executing overseas projects. We argue that it is important to understand firms' motivations to constitute collaborative ventures before investigating the problem of embeddedness in networks. Thus, our survey was designed to obtain knowledge necessary for establishing a theoretical foundation about collaborative entry for overseas projects.

The target population for our survey was defined as practitioners working for Korean contractors with at least 10 years of experience in overseas construction projects. A random sample of 160 practitioners was used for the survey (60 from large-sized contractors and 100 from small/medium-sized firms). Respondents were requested to rate the weight of strategic motives for collaborative entry for overseas projects, which are listed in Table 1. A questionnaire consisting of a 7-point Likert-scale series of questions (not at all important: $1 \sim$ extremely important: 7) was tailored to help respondents recall experiences and express their opinions. As a result, 28 practitioners from large firms and 30 practitioners from small/mediumsize firms responded, for a response rate of $36.2 \%$.

The survey identified that large firms primarily intended to establish collaborative ventures to benefit from partners' complementary roles in executing projects. On the other hand, small/medium-size firms were looking to take advantage of the management capabilities of large firms and the opportunity to explore new markets by constituting collaborative ventures (Table 1). In particular, respondents from large firms ranked the following as the most important reasons for pursuing a partnership: (1) the need for the partner's specialized knowledge; (2) the desire to maximize organizational flexibility and effectiveness through outsourcing; (3) the lack of local specialty contractors; (4) the desire to share cost risks; (5) trust regarding the responsibility and sincerity of domestic partners; and (6) the late participation in a project that a partner led off. Respondents from small/medium-size firms ranked the following as the most important reasons for pursuing a partnership: (1) the lack of ability for risk management; (2) executive's initiative; (3) the difficulty in receiving independent orders from foreign contractors; and (4) intense competition in domestic markets.

Table 1. Strategic motives for collaborative entry

\begin{tabular}{lc}
\hline \multicolumn{1}{c}{ Large firms' perspective } & Mean \\
\hline Need for a partner's specialty & 5.37 \\
\hline Desire to maximize organizational flexibility and effectiveness through outsourcing & 5.27 \\
\hline Lack of local specialty contractors and human resources & 5.17 \\
\hline Desire to share cost risk with partners & 5.13 \\
\hline Trust regarding responsibility and sincerity of domestic partners & 4.89 \\
\hline Late participation in a project that a partner led off & 4.55 \\
\hline No language barrier with domestic partners & 3.86 \\
\hline Enforcement of collaborative entry by agreements & 3.82 \\
\hline \multicolumn{1}{c}{ Small/medium sized firms' perspective } & 5.27 \\
\hline Lack of ability for risk management & 4.92 \\
\hline Executive's initiative & 4.78 \\
\hline Difficulty of receiving independent orders from foreign contractors & 4.50 \\
\hline Intense competition in domestic market & 4.35 \\
\hline Requirement for collaborative entry for a project that it already led off & 4.25 \\
\hline Possession of superior specialty competent in the international construction market & \\
\hline$* *$ Questionnaires consisted of seven-point Liker-scale questions; & \\
\hline
\end{tabular}




\section{Structural and relational embeddedness in inter-firm network}

With an atomistic market model view, the results in Table 1 may seem to indicate that the partner selection for firms to constitute collaborative ventures is a purely selfinterested and profit-seeking process. Presumably, large firms who have full access to information about market conditions evaluate candidate partners and choose firms that could provide the greatest economic returns and vice versa. Specifically, large firms would like partners who are most skilled and able to share cost risk while small/medium sized firms would want large firms that are experienced enough to cope with various risks in overseas projects. Yet, whenever another firm is likely to produce higher profits for a new project, they would simply replace the current partner. In such an idealized market, there are no faithful, personal, or long-term relationships; firms are purely opportunistic and do not pay attention to mitigating uncertainty that might be of great prevalence in a real situation.

Consequently, it is likely that the network would have only a few firms of high prestige. Prestige refers to how prominent an actor is in a network. Providing that a subcontractual relationship from a large firm to a small/medium sized firm in a collaborative venture is a directed relation, only a few most skilful specialty contractors would always be selected by large contractors, thereby becoming most prestigious in the network. Furthermore, it can be assumed that the inter-firm network for overseas projects would have the properties of a scale-free network (Fig. 1), which follows a power-law distribution, considering the existence of exceedingly prestigious actors, called hubs. Power-law distributions have been empirically found to occur in many situations including the Internet (Barabási et al. 2000), the distribution of income (Levy, Solomon 1997; Dragulescu, Yakovenko 2001), the size of firms (Axtell 2001), and the magnitude of recessions (Ormerod, Mounfield 2001) and have significant consequences for our understanding of natural and man-made systems (Clauset et al. 2007). The degree distribution of many social networks is also known to follow a power-law distribution (Amaral et al. 2000; Adamic et al. 2001; Barabási et al. 2002). The most significant characteristic of scale-free networks is that a few hubs are linked with many actors and the rest are connected to a few, as illustrated in Figure 1.

A preferential attachment process, which refers to the tendency of a new actor to preferentially form relations with high popularity actors, increases the number of relations among actors as the network grows. This preferential attachment process has been suggested as an underlying mechanism for generating power-law distributions (Barabási, Albert 1999). As such, small/medium sized firms do not have an equal chance to be selected by large firms. A large firm would preferentially choose a partner who appears to be most attractive in terms of project execution. As more projects are performed and the inter-firm network grows, small/medium sized firms that have been selected frequently and thus have expe-

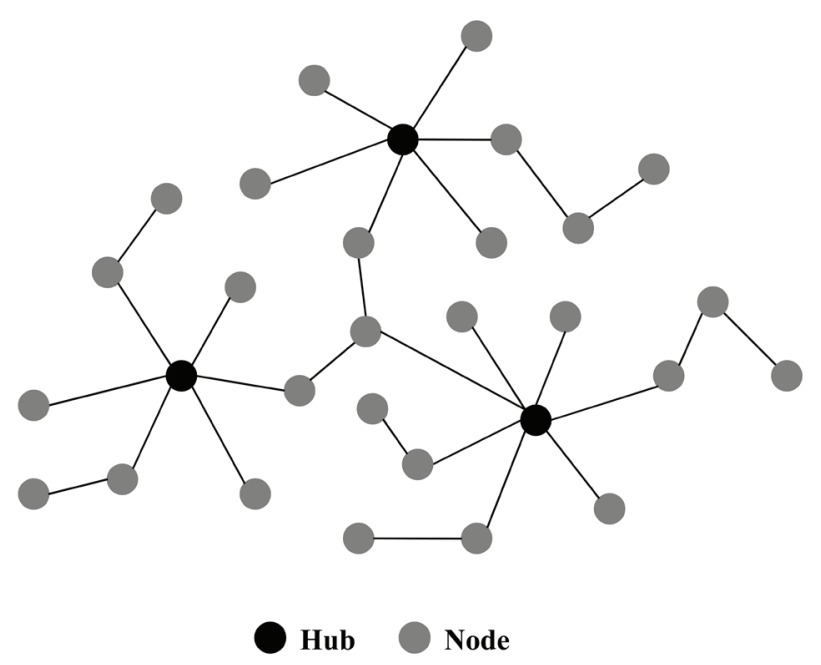

Fig. 1. A typical scale-free network

rienced overseas projects become more noticeable and more likely to be selected in the network. They turn into hubs in the inter-firm network whose distribution of relations would follow a power-law distribution.

However, a firm's partner choice in a wide firm network cannot be solely based on a self-interested and profit-seeking action, but one constrained by the firm's embeddedness in social relations. In other words, it is not merely an economic process, but a process sustained by and anchored in a social context (Jack, Anderson 2002). In fact, it is unlikely that a firm behaves in an economically optimized manner all the time in a complex and dynamic market. We should take into consideration firms' relational properties and overall network structure as well as economic behaviour models.

The reasons why firms' economic behaviours become embedded in inter-firm networks can be threefold. First, firms are boundedly rational entities and therefore cannot have perfect information regarding other firms, unlike the assumptions of neoclassical economics. A firm has to make decisions with limited information. Besides, firms have limits in their capability to recognize and solve complex problems. As Romo and Schwartz (1995) mentioned, imperfect information and bounded rationality often induce seeking for mitigating uncertainty in complex business environments, thereby having longterm relationships rather frequently changing partners.

Second, firms are also myopic in the sense that they cannot have perfect information on a complex inter-firm network. Firms might not be fully aware of who plays in the network as well as who has connections with whom. They might be able to see only a partial boundary of the whole networks. For example, company A in Figure 2 is aware of its closest neighbours (connected by thicker lines) including B, but it is likely not capable of knowing about $\mathrm{C}$, given the multiple connections and partners between $\mathrm{A}$ and $\mathrm{C}$. In some complex networks, nodes are thought of being connected via paths composed of indirect relations. However, in this paper, we do not consider 


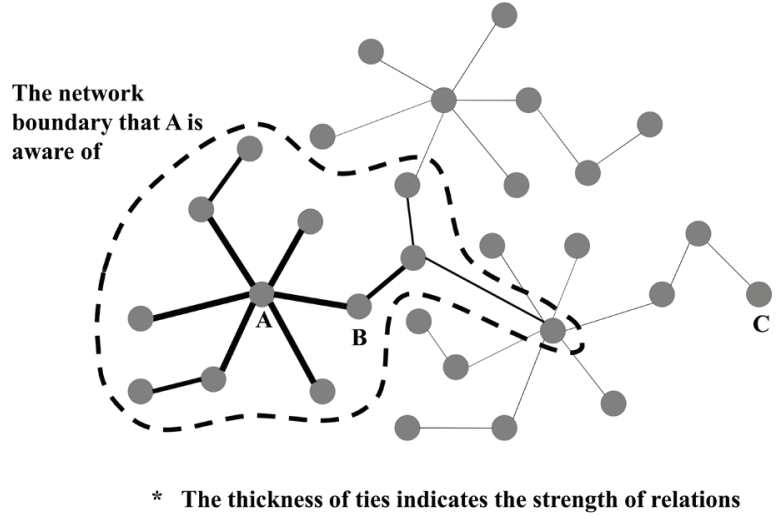

Fig. 2. The myopic view phenomenon in a network

such relations because relations of great distance are expensive to maintain (Watts 2001). Therefore, a firm has to search for a partner within the observed boundary. That myopic view keeps a firm from economically optimizing decision-making thus resulting in locally optimized partners.

Last, firms are often connected by personal, trustbased, or conglomerate-based relationships. Therefore, they sometimes make relationships via personal routes or develop trust-based relations with partners rather than using an optimized partner-evaluation method. This seems contradictory to a self-interested and profit-seeking approach where a firm seeks immediate benefit from current relations. Indeed, a firm may make no profit or even lose money in forming those relationships. However, what may seem irrational or altruistic is actually consciously opportunistic and selfish behaviour since companies are going after a superior position in the network, by which they can establish long-term relationships with promising partners and secure business opportunities in overseas markets.

Given this reality, we argue that structural embeddedness affects the economic behaviour of firms by facilitating or inhibiting social interactions as a whole. For instance, a firm having diverse contacts can access information through different routes, making comprehensive decisions and exploring more business opportunities. Alternatively, a firm's participating in cohesive subgroups can take advantage of proximity and trustworthiness in closed networks. Firms in a closed network can easily interact with each other and reinforced norms of exchange in the network enhancing trustworthiness for other members (Coleman 1988). The resulting social cohesion reduces exchange risks and promotes cooperation within the group (Moran 2005). On the other hand, a firm whose relationships are sparse but span over split groups can create a competitive advantage (Granovetter 1973; Burt 1992). A firm of cohesive relations is likely to have redundant information circulating with the group, whereas a firm filling the gaps among different groups is more likely to obtain information that is non-redundant. This firm can also use its positional advantage connecting different sides. Bonacich (1987) upheld the significance of possessing a central position with the potential for control of information flow. When a firm not only has diverse relations but also is connected to partners of great power, the firm occupies a central position and could influence others by withholding information or distorting it in transmission.

In addition, the economic behaviour of a firm is constrained by the strength and quality of relations beyond the density and quantity, that is, relational embeddedness. The strength and quality of relations are determined by past experience, trustworthiness, reciprocity, and alliance stipulations among firms. Strong relations constitute a base of trust that can reduce resistance and provide comfort in the face of uncertainty (Krackhardt 1992) and also avoid disruptive conflicts (Nelson 1989). It consequentially affects how likely firms are willing to share accesses to critical information and provide resources and know-how.

\section{Empirical study}

Based on the considerations above, we analysed the collaborative entry cases among Korean construction firms for overseas construction projects from 1990 to 2007. Information on 384 projects conducted by 207 companies (50 general contractors and 157 specialty contractors) was collected. The data were collected with the support of International Contractors Association of Korea (ICAK) to which Korean firms are obliged to report the record of their overseas projects. We limited the scope of analysis to collaboration between large firms and small/medium sized firms not only because it is collaboration between large firms and small/medium sized firms - mostly as general contractors and subcontractors - that could produce the greatest benefit, but also because it was actually found that most collected cases are between large firms and small/medium sized firms.

Social network analysis and statistical methods were employed to present evidence of structural embeddedness by computing network measures and producing social network-related graphs, examining the impact of embeddedness on project performance. Several social network measures are used in this study. Because a relation in inter-firm network can be formed when a firm makes a contract with other firms, the network is modelled as a directed graph - in general, relations were formed from large firms to small/medium firms in our data. Indegree is the number of incoming relations a firm has whereas outdegree is the number of outgoing relations. Efficiency was employed to examine the tendency of structural hole (Burt 1992). Efficiency formulates the effective size of a firm's network by its actual size. It tells us how much impact a firm has on partners (Hanneman, Riddle 2005). Because the inter-firm network shapes a hierarchical structure, large firms often constitute the root of completely disconnected firms and small/medium sized firms have only one incoming relation, so that efficiency measure ends up being one. Firms 
with meaningless efficiency values and extreme profit levels were considered outliers and were removed from consideration. Bonacich-power (Bonacich 1987) was used as a centrality measure. Bonacich-Power considers not only a firm's relations, but also its neighbors' relations to compute centrality. The underlying idea is that being connected to central partners makes a firm more powerful, so that it has a dominant place for controlling information and resource flow. The influence of neighbours attenuates proportionally to distance. These ideas are consistent with a firms' myopic behaviour in structural embeddedness. Clustering coefficient at a firm level is a measure showing the extent to which a firm lives in clustered neighbourhoods. For the same reason as efficiency, firms with clustering coefficients of 0 were excluded to avoid invalid data.

The data was tested through several hypotheses developed on the basis of preceding discussion. In order to determine whether the inter-firm network is constrained by embeddedness, we stated that (A) the indegree distribution of the inter-firm network follows a power-law distribution with variances (Hypothesis 1) and (B) the inter-firm network has stronger tendency of forming cohesive subgroups than complete scale-free networks (Hypothesis 2). In order to test the extent to which social network characteristics explaining structural embeddedness of firms are related with performance, we stated that (A) the more relations firms have, the higher profit they generate (Hypothesis 3), (B) The stronger tendency of forming cohesive subgroups firms have, the higher profit they generate (Hypothesis 4), (C) the more powerful position firms have in networks, the higher profit they generate (Hypothesis 5) and (D) The more central position firms have in networks, the higher profit they generate (Hypothesis 6).

An ethnographic study was also conducted to address the problem of relational embeddedness. Because of the lack of data to measure relational embeddedness (e.g. we could not obtain data on firms' past experiences, trustworthiness, reciprocity, and alliance stipulations), it was not possible for us to perform an integrated analysis as in Uzzi (1996). However, because relational embeddedness is indispensable in understanding the problem of embeddedness, instead of excluding it from our study, we decided to interview a number of industry experts to qualitatively identify the effect of relational embeddedness in collaborative ventures for overseas projects. We believe that this ethnographic approach still provides pragmatic evidence to expand our understanding on the ecological nature of collaborative relations.

\subsection{Data description}

Our data is summarized in Table 2 and graphically depicted in Figure 3. There are 207 nodes and 384 ties in total. The density of the network that denotes the proportion of possible relations that are actually present in the network is 0.009005 and hence the aver- age number of relations (degree) that firms have 1.855 $(=206 \times 0.009005)$. Distance in SNA is used to measure how many steps a node needs to go through to reach other nodes. The average distance in the inter-firm network is 2.830 and a network diameter which is the largest value of distance in the network is 7 .

Outdegree distribution widely spreads out while indegree distribution peaks up, mostly having only 1 indegree as shown in Figure 4. It could be stated that large firms, which typically receive orders, have relatively equivalent power in overseas construction markets, while only several small/medium sized firms possess competent aspects to induce large firms to choose them. There are both large and small/medium sized firms that are dominating the market. Six dominant large firms account for $59.6 \%$ of the market in terms of outdegree and three dominant small/medium firms account for $13.5 \%$ of the market in terms of indegree.

\subsection{Results and discussions}

Indegree distribution was examined to test the extent to which it follows a power-law distribution (Hypothesis 1) that is, whether it has properties of a pseudo scale-free network. Indegree distribution is fitted following Clauset et al. (2007) method using a "plfit" function (Dubroca 2008). In particular, power-law distributions have the form: $\mathrm{p}(\mathrm{x})=$ $\mathrm{Cx}^{-\alpha}$. On a log-log space, the power-law equation is $\log (\mathrm{p}(\mathrm{x}))=\mathrm{c}-\alpha \log (\mathrm{x})$ which has the form of a linear relation with the slope of $\alpha$. When the $\alpha$ of a network is between 2 and 3, the network is called a scale-free network. The indegree-proportion graph is transformed into a log-log space in order to see whether indegree distribution follows a power-law distribution and to estimate $\alpha$ (Fig. 5). As a result, $\alpha$ in the inter-firm network has a value of 2.37 and the Kolmogov-Smirnov d-statistics (0.0795) is less than the critical value (0.0945) at the 0.05 significance level. Accordingly, we cannot reject the null hypothesis that the indegree distribution is not different from the hypothesized power-law distribution and it is identified that the inter-firm network has the properties of a scale-free network in the range of indegree $>1$.

However, the degree distribution does not always fit into a power-law distribution in all ranges. We argue that this is because transactions in the inter-firm network do not happen with a pure preferential attachment process but, to some extent, they are affected by the social context as we have discussed earlier. For this reason, the interfirm network might exhibit some variance from a perfect fit into a power-law distribution unlike other networks

Table 2. Descriptive summary

\begin{tabular}{lccc}
\hline Number of nodes & 207 & Number of ties & 384 \\
\hline Network diameter & 7 & Density & 0.009005 \\
\hline Average degree & 1.855 & $\begin{array}{l}\text { Average } \\
\text { distance }\end{array}$ & 2.830 \\
\hline
\end{tabular}




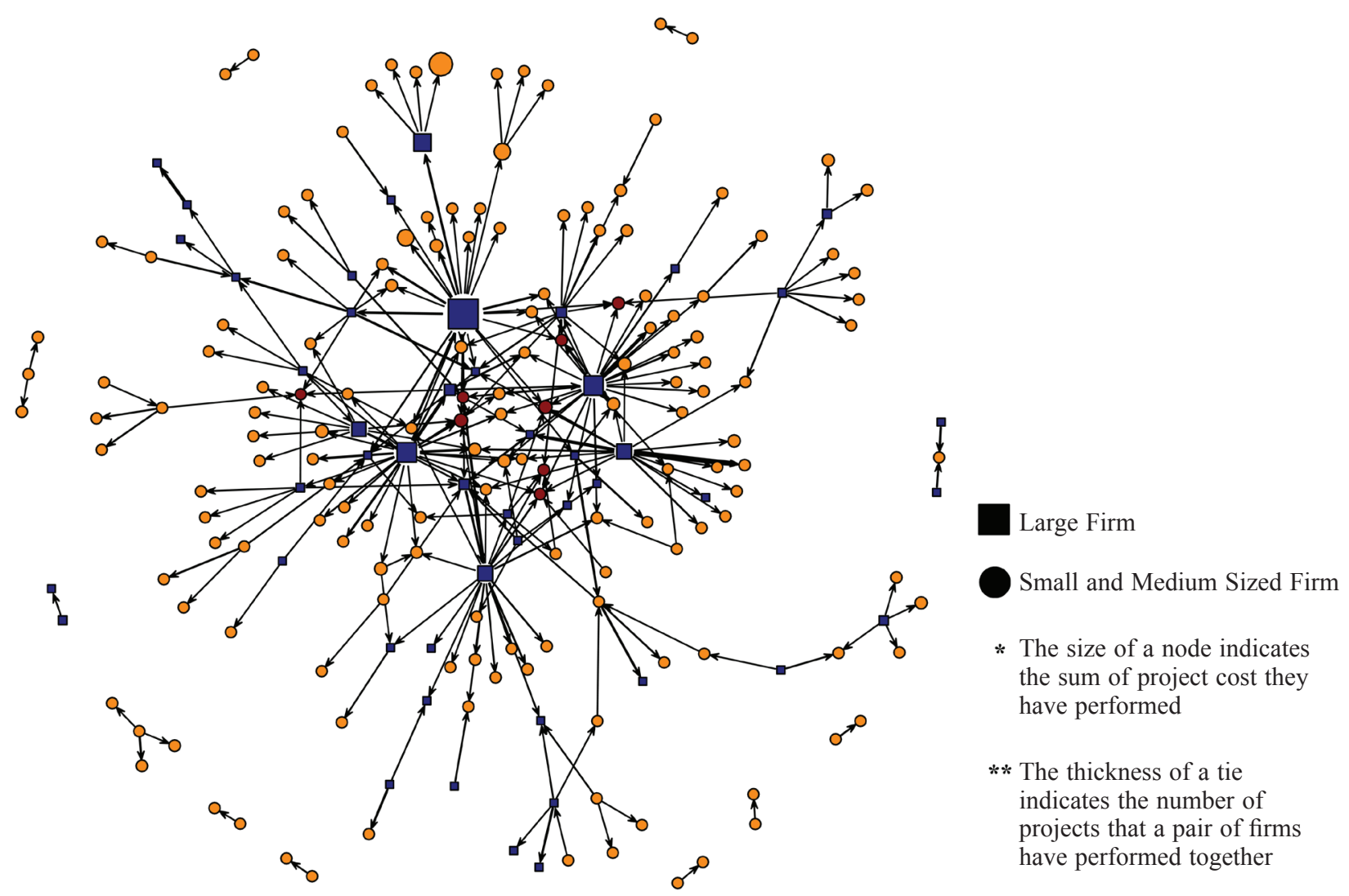

Fig. 3. Sociogram of inter-firm network
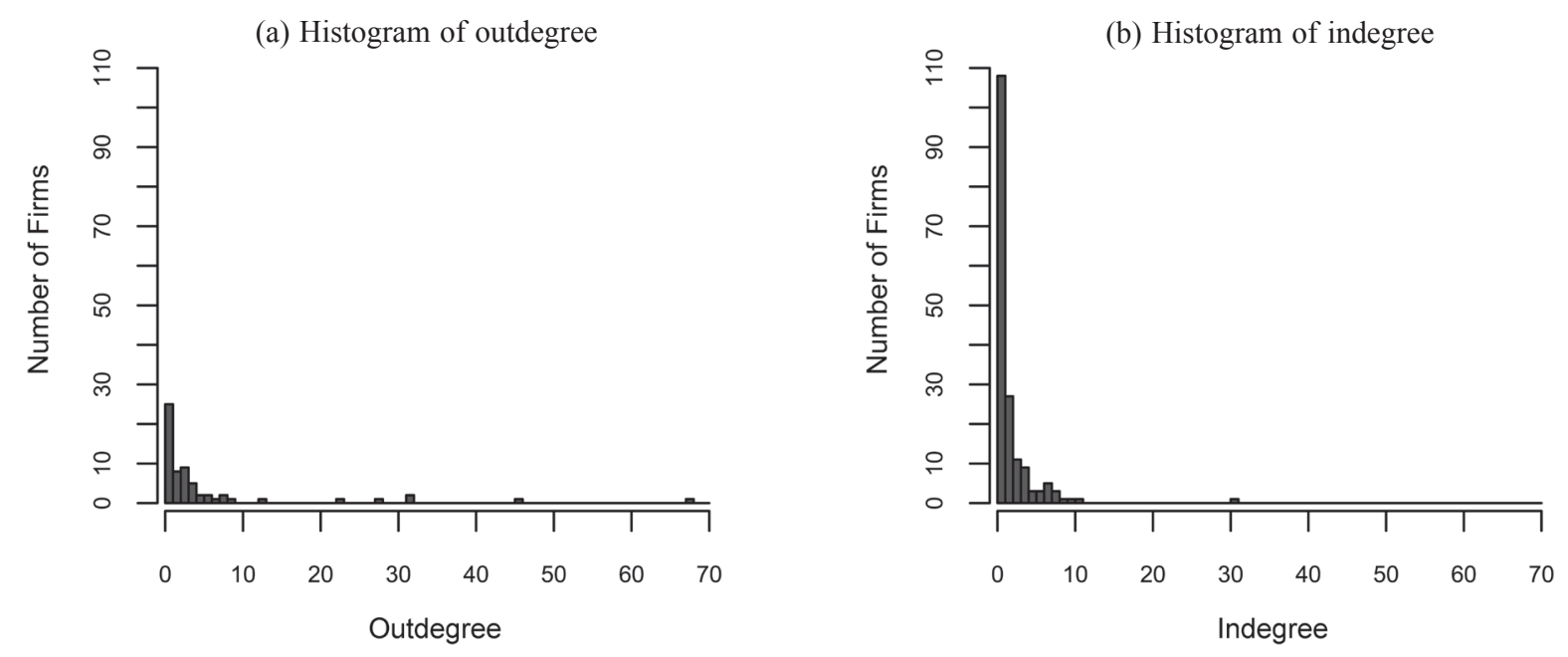

Fig. 4. Outdegree distribution (a), indegree distribution (b)

where a process close to a pure preferential attachment could happen such in Amazon and MSN (Cano et al. 2006). In this regard, these results underpin the claim that partner selection of firms is determined not only by economics reasons, but also social relations.

The extent to which firms form cohesive relations was tested (Hypothesis 2). As a whole, the overall weighted graph-clustering coefficient was found to be 0.020 . Even though this value is not directly comparable with that of complete scale-free networks because it can vary significantly with other network properties, this value is rather high, as compared with the overall density (0.009005) of the network. This implies that local neighbourhoods are denser than the overall network and so there seems to be a tendency to form local cohesive subgroups.

In order to more closely examine the existence of cohesive subgroups, firms were separated through a partitioning method that searches for a combination of subgroups in a way that maximizes relations within a group and minimizes relations between different groups. The results are shown in the form of a simplified density table (Table 3). Density values show how strongly firms 
(a)

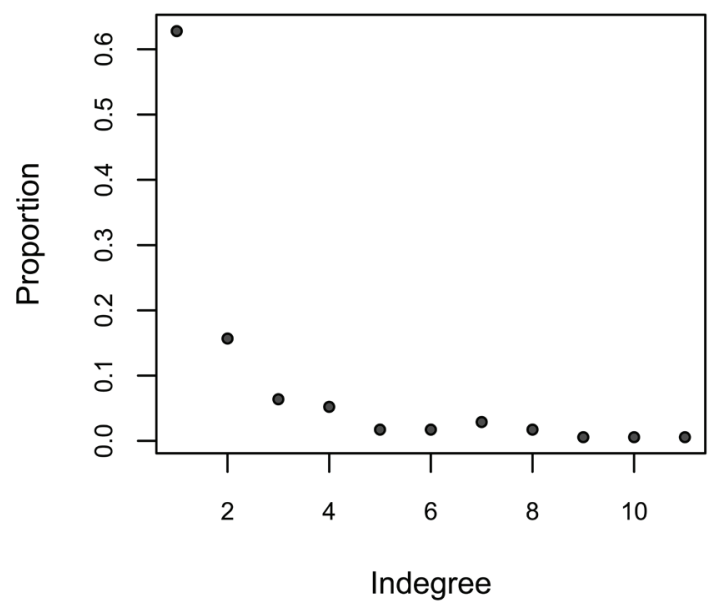

(b)

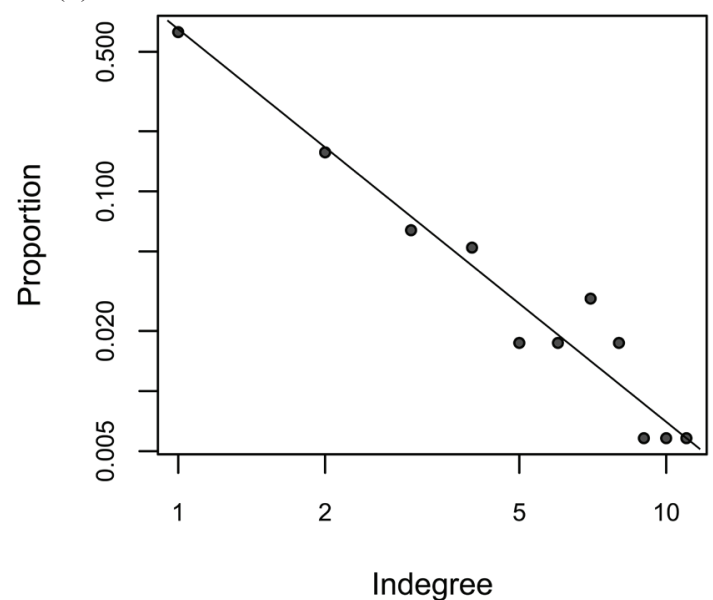

Fig. 5. Distribution of indegree proportion (a), log-log space transformation (b)

within a subgroup are connected in diagonal and firms between different subgroups in off-diagonal, from subgroups in rows to subgroups in columns. The data shows 14 cohesive subgroups, 4 semi-isolated subgroups, and 1 isolated subgroup. Specifically, G1, G2, G4, and G6 are semi-isolated in that they only have weak and incoming relations. For instance, G2 has one weak (0.01) and incoming relation from G12. G9 is isolated in a similar fashion. On the contrary, some subgroups take a role of connecting disjointed subgroups. G8, G12, and G13 are the most connected subgroups.

The reduced graph in Figure 6 conveys this information in a more intuitive way. The relations among subgroups are represented with nodes and lines whose thicknesses are proportional to the strength of the relations. Reflexive lines are used for representing within-subgroup relations and dotted lines for very sparse within-subgroup relations.
To illustrate, a firm in isolated subgroups such as G2 are considered as having a strong tendency to make relations only with firms in the subgroup, whereas some firms in G12 have a strong tendency to form relations with firms in G10, G7, and G13 as well as their subgroup.

A strong tendency of firms making cohesive subgroups was identified. However, it should be noted that they are not densely interconnected clans, but rather hierarchical structures starting from a large firm reaching to separate small/medium sized firms as shown in Figure 3. In other words, the networks retained endogamic characteristics in the sense that a great majority of smaller firms had worked with only one large firm, forming subgroups. This finding also sustains the affirmation that firms often like to maintain personal, trust-based, or conglomeratebased relationships rather than merely arm's-length relationships by contracts.

Table 3. Density table

\begin{tabular}{|c|c|c|c|c|c|c|c|c|c|c|c|c|c|c|}
\hline Group & G1 & G2 & G3 & G4 & G5 & G6 & G7 & G8 & G9 & G10 & G11 & G12 & G13 & G14 \\
\hline G1 & 0.07 & 0 & 0 & 0 & 0 & 0 & 0 & 0 & 0 & 0 & 0 & 0 & 0 & 0 \\
\hline G2 & 0 & 0.08 & 0 & 0 & 0 & 0 & 0 & 0 & 0 & 0 & 0 & 0 & 0 & 0 \\
\hline G3 & 0 & 0 & 0.04 & 0 & 0 & 0 & 0 & 0 & 0 & 0 & 0 & 0 & 0 & 0 \\
\hline G4 & 0 & 0 & 0 & 0.07 & 0 & 0 & 0 & 0 & 0 & 0 & 0 & 0 & 0 & 0 \\
\hline G5 & 0 & 0 & 0 & 0 & 0.05 & 0 & 0 & 0 & 0 & 0 & 0 & 0 & 0 & 0 \\
\hline G6 & 0.01 & 0 & 0 & 0 & 0 & 0.06 & 0 & 0 & 0 & 0 & 0 & 0 & 0 & 0 \\
\hline G7 & 0.01 & 0 & 0 & 0 & 0 & 0 & 0.06 & 0 & 0 & 0 & 0 & 0 & 0 & 0 \\
\hline G8 & 0.01 & 0 & 0.06 & 0 & 0 & 0.02 & 0.02 & 0.10 & 0 & 0.02 & 0.05 & 0 & 0 & 0.03 \\
\hline G9 & 0 & 0 & 0 & 0 & 0 & 0 & 0 & 0 & 0.06 & 0 & 0 & 0 & 0 & 0 \\
\hline G10 & 0.01 & 0 & 0 & 0.01 & 0.02 & 0.01 & 0.02 & 0.01 & 0 & 0.09 & 0 & 0 & 0 & 0 \\
\hline G11 & 0 & 0 & 0 & 0 & 0 & 0 & 0 & 0 & 0 & 0 & 0.02 & 0 & 0 & 0 \\
\hline G12 & 0.01 & 0.01 & 0 & 0 & 0.02 & 0 & 0.03 & 0.01 & 0 & 0.03 & 0 & 0.07 & 0.03 & 0.01 \\
\hline G13 & 0.02 & 0 & 0.03 & 0 & 0.03 & 0 & 0.01 & 0.12 & 0 & 0 & 0.02 & 0 & 0.07 & 0 \\
\hline G14 & 0.01 & 0 & 0 & 0.01 & 0 & 0 & 0 & 0.04 & 0 & 0.01 & 0.01 & 0 & 0 & 0.07 \\
\hline
\end{tabular}




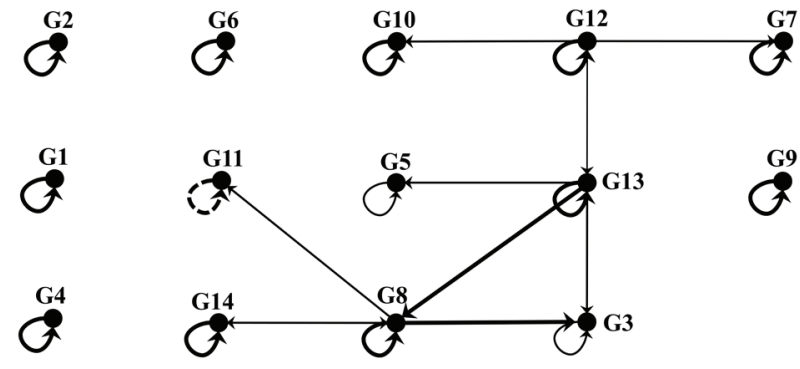

Fig. 6. Reduced graph

We tested the data to determine the extent to which social network characteristics explaining structural embeddedness of firms (e.g. indegree, outdegree, structural hole, centrality, and cohesion) are related with performance. We conducted ordinary least square regression analysis between average profit and network measures. When suspicious of the significant effect of extreme values on the result, we conducted robust regression or excluded outliers. We used average profit of firms, as a dependent variable, to measure efficiency of relations. The reasons are two folds. First, firms are seeking partners with which they think to produce a certain level of profit, while comprehensively considering reasons listed in Table 1 rather than pursuing only one of them. Second, possessing a superior position in networks would allow a firm higher chance to have a partner of greater expected profitability.

Results show that average profit has a positive relation with indegree, outdegree, efficiency, and BonacichPower centrality, but a negative relation with clustering coefficient (Fig. 7). Although only indegree, outdegree, and clustering coefficient exhibit a significant outcome at the 0.1 significance level, the other measures also provide plausible evidence of the impact of structural embeddedness on average profits. In particular, the more diverse relations (indegree and outdegree) firms have, the higher profit they have earned in both large firms and small/ medium sized firms (Hypothesis 3). The results can be interpreted by stating that large firms of higher outdegree were able to select a partner among a greater pool so that they could better satisfy their needs. Regarding small/medium sized firms, on the one hand, it is more likely that they were selected because they possessed a superior specialty, but on the other hand, it might also be because they have sustained long-term relationships with a few exclusive large firms.

Our analysis showed that the stronger the tendency of cohesion, the lower the profit (Hypothesis 4). This is likely because strong cohesive relations within a group keep a firm from changing business routes, failing to reduce risks and maximize profitability. The results also indicate that firms connecting split groups have made a higher profit (efficiency). This finding is consistent with the view that firms mediating between other firms that are not linked have more control over information and resource flow and thus have a greater opportunity to make a profit (Hypothesis 5).
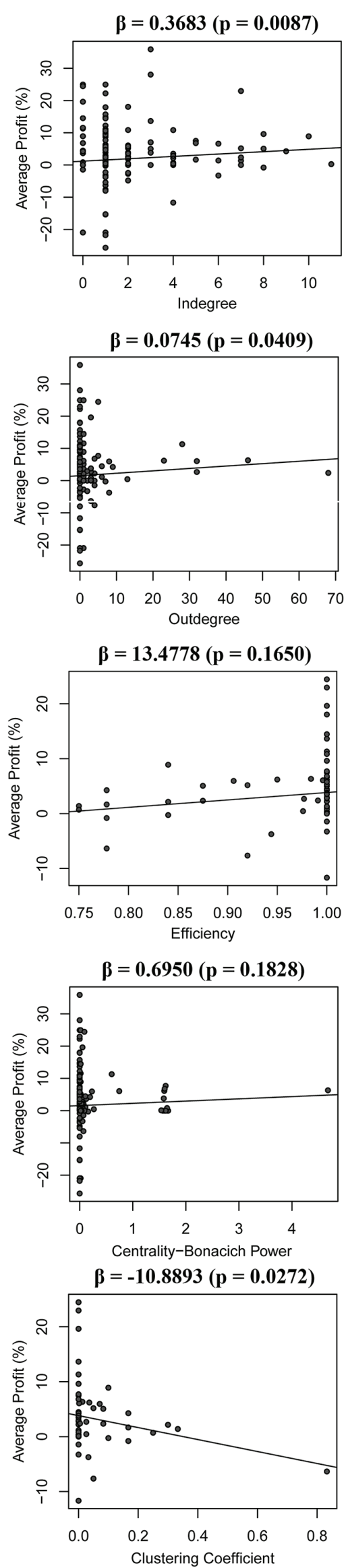

Fig. 7. Relation of firms' average profit with network properties 
Bonacich-power as a centrality measure (Hypothesis 6) did not produce a significant outcome, but shows a general positive relation with average profit.

\subsection{Ethnographic study}

Following the investigation of structural embeddedness, an ethnographic study was conducted to obtain supporting evidence on the effect of relational embeddedness. We interviewed fourteen industry experts, seven from large firms and seven from small/medium sized firms. These experts have 25 years of experience, on average, in marketing and managing overseas projects. A semi-structured face-to-face interview method was used, were interviewees were guided to recall past experiences and offer their opinions after providing them with specific topics of conversation as well as previous research findings.

Most interviewees empirically recognized the impact of relational embeddedness in the inter-firm network above all, trust-based long-term relationships. Some pointed out that whereas it had been generally preferable for large firms to choose partners from a pool of candidate companies because of cost competitiveness and technology accessibility, it is also essential for firms to maintain trust-based long-term relationships with strong partners to extend their network boundary and take a central role as network-makers, emphasizing the fact that quality of network on a trust basis could significantly affect the firms' performance. Some also confirmed that such trust-based relationships enabled firms to reduce uncertainty in entering new businesses and to ensure more business opportunities through sharing information and know-how, guaranteeing market share, and negotiating more reasonable unit prices.

\section{Conclusions}

The concept of embeddedness in inter-firm networks for overseas construction projects is investigated in this paper and the reasons why firms' behaviours become embedded in the network is explained. First, we have shown that the inter-firm network of overseas construction projects exhibits the properties of a scale-free network with variance from a perfect fit. This result indicates that transactions in the inter-firm network do not follow a pure preferential attachment process but, to some extent, they are affected by the social context; otherwise, the inter-firm network would be perfectly a scale-free network. Also, the finding that there is a strong tendency of firms making cohesive subgroups holds that argument. Second, statistical analysis indicated that average profits had a positive relation with indegree, outdegree, efficiency, and centrality. These results confirmed the advantage of having diverse relations and occupying a superior position in networks which has been reported in previous studies (Granovetter 1973; Burt 1992). Third, it is shown that average profits had a negative relation with the clustering coefficient. This seems because strong cohesive relations prevent a firm from changing business routes, failing to reduce risks and maximize profitability. This is opposed to former findings in Coleman (1988) and Moran (2005). In addition, an ethnographic study revealed that there is plausible evidence of the impact of relational embeddedness.

This study put forward a expanded theoretical explanation on firms' embeddedness in an inter-firm network in international construction by incorporating firm-level explanations, e.g. bounded rationality, myopic views in networks, and trust-based relations with partners, with a current view. This study also strengthened the theoretical foundations of embeddedness through presenting empirical evidence. This expanded view of embeddedness of firms in an inter-firm network is expected to provide some recommendations to practitioners and firms. First, it is recommend to understand that our economic decision and behaviour cannot but be affected by social context. Second, finding partners to form a collaborative venture for overseas projects, a firm had better to make sure that it maintains diverse relations through which it can make comprehensive decisions and explore more business opportunities.

This study has several limitations. First, it does not include an integrated analysis of both structural embeddedness and relational embeddedness due to the difficulty of getting data to evaluate relational embeddedness. Relational embeddedness is mostly associated with past experiences, trustworthiness, reciprocity, and alliance stipulations. Developing and collecting an appropriate relational embeddedness measure would significantly enhance our understanding of its role on profitability. Second, although the evolution of the inter-firm network is a dynamic process in nature, no longitudinal analysis was conducted. It is recommended that inter-firm network studies expand into a longitudinal axis. Third, this research effort is meant to expand the traditional view toward the behaviour of economic entities by integrating social aspects, but does not yet fully incorporate a realistic model of economic entities and social environments. Developing a model of firms' preferential decisionmaking and economic behaviour, understanding social principles in the inter-firm network, and implementing an integrated model would help in understanding the characteristics of inter-firm networks. Last, the data analysis is confined in Korea though the theoretical background of embeddnedness is not limited to a specific situation or region, but rather assumes a universal decision-making condition such as imperfect information and bounded rationality, which has been found in several industries. We recommend that researchers expand this view in future research - e.g. collaborative ventures between general contractors from one country and subcontractors form the other countries.

\section{Acknowledgements}

The authors are most grateful to ICAK (International Contractor Association of Korea) for providing useful data for the analysis. The individuals and companies conducting expert interviews or providing valuable comments should be acknowledged. This research was sup- 
ported by Basic Science Research Program through the National Research Foundation of Korea (NRF) grant funded by the Ministry of Education, Science and Technology (2012-0000178) and by Basic Science Research Program through the National Research Foundation of Korea (NRF) funded by the Ministry of Science, ICT and Future Planning (No. NRF-2013R1A1A1010562). This work also was supported by the Ewha Womans University Research Grant of 2012.

\section{References}

Adamic, L. A.; Lukose, R. M.; Puniyani, A. R.; Huberman, B. A. 2001. Search in power-law networks, Physical Review E 64(4): 8 p. http://dx.doi.org/10.1103/PhysRevE.64.046135

Amaral, L. A. N.; Scala, A.; Barthelemy, M.; Stanley, H. E. 2000. Classes of small-world networks, Proceedings of the National Academy of Sciences 97(21): 11149-11152. http://dx.doi.org/10.1073/pnas.200327197

Asanuma, B. 1985. The organization of parts purchases in the Japanese automotive industry, Japanese Economic Studies 13: 32-53.

Ashley, D. B. 1987. Political risks in international construction, Journal of Construction Engineering and Management 113(3): 447-467.

http://dx.doi.org/10.1061/(ASCE)0733-9364(1987)113:3(447)

Axtell, R. L. 2001. Zipf distribution of US firm sizes, Science 293(5536): 1818-1820. http://dx.doi.org/10.1126/science.1062081

Barabási, A.-L.; Albert, R. 1999. Emergence of scaling in random networks, Science 286(5439): 509-512. http://dx.doi.org/10.1126/science.286.5439.509

Barabási, A.-L.; Albert, R.; Jeong, H.; Bianconi, G. 2000. Power-law distribution of the World Wide Web, Science 287(5461): 2115. http://dx.doi.org/10.1126/science.287.5461.2115a

Barabási, A.-L.; Jeong, H.; Neda, Z.; Ravasz, E.; Schubert, A.; Vicsek, T. 2002. Evolution of the social network of scientific collaborations, Physica A: Statistical Mechanics and its Applications 311(3-4): 590-614. http://dx.doi.org/10.1016/S0378-4371(02)00736-7

Bonacich, P. 1987. Power and centrality: a family of measures, American Journal of Sociology 92(5):1170-1182. http://dx.doi.org/10.1086/228631

Burt, R. S. 1992. Structural holes. Cambridge, MA: Harvard University Press. 313 p.

Cano, P.; Celma, O.; Koppenberger, M.; Buld, J. M. 2006. Topology of music recommendation networks, Chaos: An Interdisciplinary Journal of Nonlinear Science 16: 013107. http://dx.doi.org/10.1063/1.2137622

Clauset, A.; Shalizi, C. R.; Newman, M. E. J. 2007. Power-law distributions in empirical data, Arxiv. 43 p. http://dx.doi.org/10.1137/070710111

Coleman, J. S. 1988. Social capital in the creation of human capital, American Journal of Sociology 94: 95-120. http://dx.doi.org/10.1086/228943

Crosthwaite, D. 2011. World construction 2011. Davis Langdon.

Demacopoulos, A. C. 1989. Foreign exchange exposure in international construction: PhD Dissertation. Massachusetts Institute of Technology, Massachusetts, USA

Dragulescu, A.; Yakovenko, V. M. 2001. Exponential and power-law probability distributions of wealth and income in the United Kingdom and the United States, Physica A: Statistical Mechanics and its Applications 299: 213-221.
Dubroca, L. 2008. Plfit [online], [cited 11 April 2012]. Available from Internet:

http://tuvalu.santafe.edu/ aaronc/powerlaws/plfit.r

Gandhi, J.; Sauser, B. 2008. Knowledge networks: how independence and subject matter experts can influence project reviews, Engineering Management Journal 20(1): 19-28.

Gnyawali, D. R.; Madhavan, R. 2001. Cooperative networks and competitive dynamics: a structural embeddedness perspective, The Academy of Management Review 26(3): 431-445.

Granovetter, M. 1985. Economic action and social structure: the problem of embeddedness, American Journal of Sociology 91: 481 p. http://dx.doi.org/10.1086/228311

Granovetter, M. S. 1973. The strength of weak ties, American Journal of Sociology 78(6): 1360-1380. http://dx.doi.org/10.1086/225469

Han, S. H.; Diekmann, J. E. 2001a. Approaches for making riskbased go/no-go decision for international projects, Journal of Construction Engineering and Management 127(4): 300-308.

http://dx.doi.org/10.1061/(ASCE)0733-9364(2001)127:4(300)

Han, S. H.; Diekmann, J. E. 2001b. Making a risk-based bid decision for overseas construction projects, Construction Management \& Economics 19(8): 765-776. http://dx.doi.org/10.1080/01446190110072860

Han, S. H.; Diekmann, J. E.; Lee, Y.; Ock, J. H. 2004. Multicriteria financial portfolio risk management for international projects, Journal of Construction Engineering and Management 130(3): 346-356.

http://dx.doi.org/10.1061/(ASCE)0733-9364(2004)130:3(346)

Han, S. H.; Kim, D. Y.; Kim, H. 2007a. Predicting profit performance for selecting candidate international construction projects, Journal of Construction Engineering and Management 133(6): 425-436.

http://dx.doi.org/10.1061/(ASCE)0733-9364(2007)133:6(425)

Han, S. H.; Park, S. H.; Kim, D. Y.; Kim, H.; Kang, Y. W. 2007b. Causes of bad profit in overseas construction projects, Journal of Construction Engineering and Management 133(12): 932-943.

http://dx.doi.org/10.1061/(ASCE)0733-9364(2007)133:12(932)

Hanlon, L. 2009. Global construction outlook. IHS Global Insight. $30 \mathrm{p}$.

Hanneman, R. A.; Riddle, M. 2005. Introduction to social network methods. Riverside, CA, University of California. 149 p.

Hastak, M.; Shaked, A. 2000. ICRAM-1: Model for international construction risk assessment, Journal of Management in Engineering 16(1): 59-69.

http://dx.doi.org/10.1061/(ASCE)0742-597X(2000)16:1(59)

Ho, S. P.; Lin, Y.-H.; Chu, W.; Wu, H.-L. 2009. Model for organizational governance structure choices in construction joint ventures, Journal of Construction Engineering and Management 135(6): 518-530.

http://dx.doi.org/10.1061/(ASCE)0733-9364(2009)135:6(518)

Jack, S. L.; Anderson, A. R. 2002. The effects of embeddedness on the entrepreneurial process, Journal of Business Venturing 17(5): 467-487. http://dx.doi.org/10.1016/S0883-9026(01)00076-3

Javernick-Will, A.; Levitt, R. 2009. Acquiring local knowledge for international projects, in Proc. of Construction Research Congress 2009, 5-7 April 2009, Seattle, Washington, 388-349. http://dx.doi.org/10.1061/41020(339)35

Koka, B. R.; Prescott, J. E. 2002. Strategic alliances as social capital: a multidimensional view, Strategic Management Journal 23(9): 795-816. http://dx.doi.org/10.1002/smj.252

Krackhardt, D. 1992. The strength of strong ties: the importance of philos in organizations, in Nohria, N.; 
Eccles, R. G. (Eds.). Networks and organizations: structure, form and action. Boston, MA: Harvard Business School Press, 216-239.

Levy, M.; Solomon, S. 1997. New evidence for the power-law distribution of wealth, Physica A 242(1-2): 90-94. http://dx.doi.org/10.1016/S0378-4371(97)00217-3

Ling, F. Y. Y.; Low, S. P.; Wang, S.; Egbelakin, T. 2008. Models for predicting project performance in China using project management practices adopted by foreign AEC firms, Journal of Construction Engineering and Management 134(12): 983-990.

http://dx.doi.org/10.1061/(ASCE)0733-9364(2008)134:12(983)

Loosemore, M. 1998. Social network analysis: using a quantitative tool within an interpretative context to explore the management of construction crises, Engineering Construction \& Architectural Management 5(4): 315-326. http://dx.doi.org/10.1108/eb021085

Mead, S. P. 2001. Using social network analysis to visualize project teams, Project Management Journal 32(4): 32-38.

Mohamed, S. 2003. Performance in international construction joint ventures: modeling perspective, Journal of Construction Engineering and Management 129(6): 619-626.

http://dx.doi.org/10.1061/(ASCE)0733-9364(2003)129:6(619)

Moran, P. 2005. Structural vs. relational embeddedness: social capital and managerial performance, Strategic Management Journal 26(12): 1129-1151. http://dx.doi.org/10.1002/smj.486

Nahapiet, J.; Ghoshal, S. 1998. Social capital, intellectual capital, and the organizational advantage, The Academy of Management Review 23(2): 242-266.

Nelson, R. E. 1989. The strength of strong ties: social networks and intergroup conflict in organizations, Academy of Management Journal 32(2) 377-401. http://dx.doi.org/10.2307/256367

Ormerod, P.; Mounfield, C. 2001. Power law distribution of the duration and magnitude of recessions in capitalist economies: breakdown of scaling, Physica A: Statistical Mechanics and its Applications 293: 573-582. http://dx.doi.org/10.1016/S0378-4371(01)00108-X

Ozorhon, B.; Arditi, D.; Dikmen, I.; Birgonul, M. T. 2008a. Effect of Partner fit in international construction joint ventures, Journal of Management in Engineering 24(1): $12-20$.

http://dx.doi.org/10.1061/(ASCE)0742-597X(2008)24:1(12)

Ozorhon, B.; Arditi, D.; Dikmen, I.; Birgonul, M. T. 2008 b. Implications of culture in the performance of international construction joint ventures, Journal of Construction Engineering and Management 134(5): 361-370.

http://dx.doi.org/10.1061/(ASCE)0733-9364(2008)134:5(361)

Ozorhon, B.; Dikmen, I.; Birgonul, M. T. 2007. Using analytic network process to predict the performance of international construction joint ventures, Journal of Management in Engineering 23(3): 156-163.

http://dx.doi.org/10.1061/(ASCE)0742-597X(2007)23:3(156)

Paul, C.; James, D.; Victor, G. 2008. Social network model of construction, Journal of Construction Engineering and Management 134(10): 804-812. http://dx.doi.org/10.1061/(ASCE)0733-9364(2008)134:10(804)

Provan, K. G. 1993. Embeddedness, interdependence, and opportunism in organizational supplier-buyer networks, Journal of Management 19(4): 841-856. http://dx.doi.org/10.1016/0149-2063(93)90030-Q
Pryke, S. D. 2005. Towards a social network theory of project governance, Construction Management \& Economics 23(9): 927-939. http://dx.doi.org/10.1080/01446190500184196

Reina, P.; Tulacz, G. J. 2011. The Top 225 international contractors, Engineering News-Record 45-66.

Romo, F. P.; Schwartz, M. 1995. The structural embeddedness of business decisions: the migration of manufacturing plants in New York State, 1960 to 1985, American Sociological Review 60(6): 874-907. http://dx.doi.org/10.2307/2096431

Schalk, J.; Torenvlied, R. 2010. Network embeddedness and public agency performance: the strength of strong ties in Dutch higher education, Journal of Public Administration Research and Theory 20(3): 629-653. http://dx.doi.org/10.1093/jopart/mup018

Sillars, D. N.; Kangari, R. 2004. Predicting organizational success within a project-based joint venture alliance, Journal of Construction Engineering and Management 130(4): 500-508.

http://dx.doi.org/10.1061/(ASCE)0733-9364(2004)130:4(500)

Simon, H. A. 1957. Models of man. New York: John Wiley and Sons. 287 p.

Siva, J.; London, K. 2012. Governmentality of megaprojects: using social network analysis to investigate client decision-making in international construction, in International Construction Business \& Management Symposium, 21-22 September 2011, Kuala Lumpur, Malaysia. 12 p.

Uzzi, B. 1996. The Sources and consequences of embeddedness for the economic performance of organizations: the network effect, American Sociological Review 61(4): 674-698. http://dx.doi.org/10.2307/2096399

Uzzi, B. 1997. Social structure and competition in interfirm networks: the paradox of embeddedness, Administrative Science Quarterly 42(1): 35-67. http://dx.doi.org/10.2307/2393808

Van Duijn, M. A. J.; Vermunt, J. K. 2006. What is special about social network analysis?, Methodology: European Journal of Research Methods for the Behavioral and Social Sciences 2(1): 2-6. http://dx.doi.org/10.1027/1614-2241.2.1.2

Walker, G.; Kogut, B.; Shan, W. 1997. Social capital, structural holes and the formation of an industry network, Organization Science 8(2): 109-125. http://dx.doi.org/10.1287/orsc.8.2.109

Wasserman, S.; Faust, K. 1994. Social network analysis: methods and applications. Cambridge, New York: Cambridge University Press. 825 p. http://dx.doi.org/10.1017/CBO9780511815478

Watts, A. 2001. A dynamic model of network formation, Games and Economic Behavior 34(2): 331-341. http://dx.doi.org/10.1006/game.2000.0803

Williamson, O. E. 1981. The economics of organization: the transaction cost approach, The American Journal of Sociology 87(3): 548-577. http://dx.doi.org/10.1086/227496

Yoshino, M. Y.; Rangan, U. S. 1995. Strategic alliances: an entrepreneurial approach to globalization. Boston: Harvard Business School Press. 259 p.

Zhi, H. 1995. Risk management for overseas construction projects, International Journal of Project Management 13(4): 231-237. http://dx.doi.org/10.1016/0263-7863(95)00015-I 
JeongWook SON. He is an Assistant Professor of the Department of Architectural Engineering at Ewha Womans University, Korea. He holds the MS in Civil Engineering from the University of Illinois at Urbana-Champaign and the PhD in Built Environment from the University of Washington. His research interests include intelligent and sustainable project management using emerging information and communication technologies, reliable project planning and control using computer simulation, enhanced collaborative disaster response in urban areas, and competitive engineering education, where he has authored and co-authored several academic journal papers.

Seung Heon HAN. He received the MS degree from Seoul National University, Seoul, Korea, and the PhD degree in Construction Engineering and Management from the University of Colorado at Boulder. He was the Director of the Ministry of Construction and Management, Korea. He was also in charge of planning, financing, and managing mega construction projects. He is currently both a Professor of the School of Civil and Environmental Engineering and the Associate Dean of College of Engineering, Yonsei University, Seoul. He is a member of the American Society of Civil Engineers. He has authored or co-authored more than 60 scholarly publications in the area of construction risk management, international project strategy, process management, issues in private investment projects, integrated performance management, and etc. His current research interests include systematic and integrated project management principles and toolkits including decision support tools, data mining technologies, and operations/processes simulations.

Eddy M. ROJAS. He is the Dean of the School of Engineering at the University of Dayton (UD). Prior to joining UD, he served as Director of the Durham School of Architectural Engineering and Construction at the University of Nebraska-Lincoln (UNL). Before joining UNL, he was a Professor in the Department of Construction Management at the University of Washington (UW), where he also served as Executive Director of the Pacific Northwest Center for Construction Research and Education and Graduate Program Coordinator. Prior to joining UW, he was an Assistant Professor in the Department of Civil, Structural, and Environmental Engineering at the University at Buffalo (SUNY). He holds graduate degrees in civil engineering (MS and PhD) and economics (MA) from the University of Colorado at Boulder and an undergraduate degree (Lic.) in civil engineering from the University of Costa Rica. Throughout his academic career, he has led numerous research studies in modeling, simulation, and visualization of construction engineering and management processes, engineering education, and construction economics. 